\title{
Sex hormone levels in females of different ages suffering from depression
}

\author{
Rong Lei ${ }^{1 \dagger}$, Yan Sun ${ }^{2 \dagger}$, Jiawen Liao ${ }^{3 \dagger}$, Yuan Yuan ${ }^{4}$, Linlin Sun ${ }^{5}$, Yugeng Liu ${ }^{6}$, Xinyu Yang ${ }^{3}$, Wenyou Ma ${ }^{7 *}$ and
} Zhenjian $\mathrm{Yu}^{7^{*}}$

\begin{abstract}
Background: There are only a few studies on sex hormones in females of different ages suffering from depression, and their conclusions are not uniform until now. This study aimed to investigate the correlation between the severity of depression in females and factors such as sex hormones and differences in sex hormone levels in females of different ages, exploring variations after treatment.

Methods: A total of 169 females with depression were selected and divided into the first-episode (91 cases) and recurrent $(78$ cases) groups. Then, on the basis of their age, the first-episode patients were divided into the young ( 48 cases, age < 45 years), perimenopausal ( 20 cases, $45-55$ years), and elderly groups ( 23 cases, age $>55$ years); the patients with recurrent depression were classified into the young (37 cases, age $<45$ years), perimenopausal ( 19 cases, $45-55$ years), and elderly groups (22 cases, age $>55$ years). The patients were assessed in accordance with the International Classification of Diseases of mental and behavioral disorders. The serum progesterone, prolactin, estradiol, and testosterone levels in the patients were measured, and differences in sex hormone levels of the groups were analyzed.

Results: The estradiol level was negatively correlated with age and the prolactin level was positively correlated with occupation. The severity of depression in females was found to be negatively correlated with age. The serum progesterone and estradiol levels in the young group were significantly higher than those in the elderly group, regardless of the first episode or recurrence. Estradiol levels in the perimenopausal and elderly groups with first-episode depression were significantly higher than those in the same group with recurrent depression. However, there was no significant difference in the serum progesterone, prolactin, estradiol, and testosterone levels in the recurrent group before and after treatment.
\end{abstract}

Conclusions: Sex hormone levels, especially estradiol, varied among females of different ages suffering from depression. Recurrent depression also has a certain effect on sex hormone levels in females. Not only should the age and relapse be considered when studying the sex hormone levels of females with depression, but also attention should be paid to whether the patients have used antidepressants before their sexual hormonal testing.

Keywords: Sex hormones, Female, Depression, Age, Estradiol

*Correspondence: mawenyou163@163.com; yuzhenjian68@163.com

${ }^{\dagger}$ Rong Lei, Yan Sun and Jiawen Liao contributed equally to this work

${ }^{7}$ Department of Clinical Psychology, Kailuan Mental Health Center

Affiliated to North China University of Science and Technology, Tangshan,

China

Full list of author information is available at the end of the article

\begin{abstract}
Background
Nowadays, depression has become one of the most common mental disorders and is regarded as the most severe disability/disease in the world [1], accounting for onethird of the social and economic cost of the global burden of disease. It is also expected to become the most socioeconomically burdened disease in the world by 2030 [2],
\end{abstract}

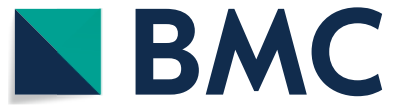

(c) The Author(s) 2021. Open Access This article is licensed under a Creative Commons Attribution 4.0 International License, which permits use, sharing, adaptation, distribution and reproduction in any medium or format, as long as you give appropriate credit to the original author(s) and the source, provide a link to the Creative Commons licence, and indicate if changes were made. The images or other third party material in this article are included in the article's Creative Commons licence, unless indicated otherwise in a credit line to the material. If material is not included in the article's Creative Commons licence and your intended use is not permitted by statutory regulation or exceeds the permitted use, you will need to obtain permission directly from the copyright holder. To view a copy of this licence, visit http://creativecommons.org/licenses/by/4.0/. The Creative Commons Public Domain Dedication waiver (http://creativeco $\mathrm{mmons}$.org/publicdomain/zero/1.0/) applies to the data made available in this article, unless otherwise stated in a credit line to the data. 
leading to a serious threat to both developed and developing countries. Its diagnosis is broad and heterogeneous that centers on low mood and/or loss of pleasure in activities. The induction of depression may be related to biology, psychology, social environment, and other factors. However, the specific mechanism is unclear. Depression appears to be more common in women than in men, with women having twice the risk as that of men. The recurrence is an important factor in determining that women are more likely to develop active depression compared to men once the first episode has occurred, but the reasons for this gender difference are not entirely clear [3]. Before puberty, girls were found to have depression levels similar to those in boys or lower [4]. Two female sex hormonesestrogen and progesterone-are considered to play a role in the onset and development of depression [5].

Studies have found that sex hormones have dramatic effects on females' lives, and anxiety-, trauma-, and stress-related disorders are modulated by sex hormones $[6,7]$. Nearly all women experience hormonal fluctuations associated with menstruation, pregnancy, and menopause, and some even undergo severe premenstrual [8] and perimenopausal/postpartum depression [9]. These women experience typical changes of reproductive hormone and suboptimal responses of the central nervous system, leading to negative effects and incommensurate behaviors [10]. Postmenopausal endocrinology is characterized by persistent low levels of ovarian steroid hormones (estradiol and progesterone) and a $50 \%$ decrease in the secretion of testosterone compared to young women. Therefore, women are more likely to develop depression at the beginning or after menopause, the severity of which is linked to fluctuations in ovarian hormone levels-particularly estrogen [11]. Moreover, studies have demonstrated that estrogen has a positive influence on the mood of middle-aged women [12]. Of note, the revised Global Consensus Statement on Menopausal Hormonal Therapy suggests that hormone therapy may be conducive to improving mood among women in early postmenopause with symptoms of depression/ anxiety [13]. Estrogen increases the synthesis and effectiveness of serotonin by reducing the activity of the serotonin-degrading enzyme monoamine oxidase inhibitor [3]. Serotonin is released into the area that regulates the amygdala's response, and involved in mood regulation. Steroid hormones, also known as neuroactive steroids, are involved in emotional and cognitive regulation through their organization and activation in the central nervous system and may be effective treatment strategies for schizophrenia and depression [3]. It is worth noting that the peripartum is also a period of dramatic changes in hormone levels. Prolactin, which is responsible for initiating and maintaining lactation, is used as one of the measurement indicators to estimate the relationship between mood and hormonal changes in postpartum women. Estrogen can stimulate the secretion of prolactin, the level of which (similar to estrogen) decreases rapidly after parturition [14]. The degree of depression is the ultimate manifestation of the interaction of these hormonal variables. As the concentration of sex hormones continues to change throughout a female's life cycle, changes in hormone levels can affect the response to antidepressant medications and the occurrence of adverse events. The induction/inhibition of estrogen and progesterone enzymes may lead to an increase/decrease in the metabolism of antidepressants during pregnancy. Thus, postmenopausal women (with decreased estradiol and progesterone levels and increased luteinizing hormone levels) may require different treatments/antidepressant dosages compared to premenopausal ones.

The sex hormone levels are affected by many factors, including age and health status, among which age are considered the main factor $[15,16]$. At the ovarian level, the number of follicles and their viability and secretions of estrogen, progesterone, inhibin, and activin fluctuate with age. However, at present, research on sex hormones in female patients of different ages suffering from depression is still relatively rare, and the conclusions are not uniform. Hence, this study aimed to compare the sex hormone levels in females of different ages suffering from depression and provide clinical references for future research on the characteristics of these hormone levels in such females.

\section{Methods \\ Patients}

This study was approved by the Ethics Committee of Kailuan Mental Health Center Affiliated to North China University of Science and Technology, Hebei, China. A total of 169 females with depression were selected between September 2017 and March 2019 at Kailuan Mental Health Center Affiliated to North China University of Science and Technology. The chief psychiatrist made the diagnosis for patients with depression according to the International Classification of Diseases (ICD10) of mental and behavioral disorders. Patients with no previous history of depressive episodes were classified as the first-episode group. Those with recurrent depressive disorder were preliminarily diagnosed using the above criteria, and finally a definitive diagnosis was made by a superior psychiatrist. The patients were divided into the first-episode (91 cases) and recurrent (78 cases) groups. Then, the first-episode patients were divided into the young (48 cases, age $<45$ years), perimenopausal (20 cases, $45-55$ years), and elderly groups ( 23 cases, age $>55$ years) on the basis of their age. Similarly, the patients 
with recurrent depression were classified into the young (37 cases, age $<45$ years), perimenopausal (19 cases, $45-55$ years), and elderly groups ( 22 cases, age $>55$ years) according to their age.

\section{Inclusion criteria}

The patients met the diagnostic criteria for depression according to the ICD-10 classification of mental and behavioral disorders.

\section{Exclusion criteria}

(1) failure to meet the inclusion criteria; (2) current/ previous neurological disorders, brain trauma, bipolar disorder, manic episodes, substance abuse (methamphetamine, cocaine, etc.), and other mental illnesses; (3) presence of severe cerebrovascular and brain diseases, such as cerebral infarction and hemorrhage; (4) women using hormones/contraceptives; (5) gynecological, immunological, endocrine, and other diseases; (6) people who dropped out or failed to complete the investigation because of other factors.

\section{Diagnostic assessment}

(1) Depressive episode typical symptoms of depression including low mood, loss of interest and pleasure, fatigue, and other common symptoms: (a) deterioration of ability to concentrate; (b) low self-evaluation and confidence; (c) sense of self-incrimination and worthlessness; (d) pessimism about the future; (e) autotomy/suicide idea or behavior; (f) sleep disorder; (g) loss of appetite. These symptoms persist for at least 2 weeks.

Mild depressive episode: At least two mild typical symptoms of depression and other common symptoms, lasting for at least 2 weeks. Moderate depressive episode: at least two mild typical symptoms of depression and three mild common symptoms (preferably four), lasting at least 2 weeks. Major depressive episode (without psychotic symptoms): three typical symptoms of depression and four or more common symptoms should generally last for 2 weeks, but it is reasonable to make this diagnosis on the basis of a course of less than 2 weeks when symptoms are extremely severe or onset is rapid. Major depressive episode (with psychiatric symptoms): meet the criteria for major depressive episodes and have delusions, hallucinations, or depressive stupor. The severity of symptoms is assessed on the basis of difficulty in completing daily tasks and social interactions, such as decreased interest/pleasure, weight and appetite changes, sleep disturbance, and significant distress or impairment in social, occupational, or other areas.

(2) Recurrent depressive disorder recurrent depression (mild/moderate/major) without independent episodes of hyperthymia and hyperactivity that meet manic criteria.
Mild recurrent depressive episode: meet the criteria for mild recurrent depressive disorder, at least two episodes, each lasting for at least 2 weeks, with no apparent mood disorder between the episodes for several months. Moderate recurrent depressive episode: meet the criteria for moderate recurrent depressive disorder, at least two episodes, each lasting for at least 2 weeks, with no apparent mood disorder between the episodes for several months. Major recurrent depressive episode (with/without psychiatric symptoms): meet the criteria for severe recurrent depressive disorder with/without psychiatric symptoms, at least two episodes, each lasting for at least 2 weeks, with no apparent mood disorder between the episodes for several months.

\section{Treatments}

Patients with recurrent depressive disorder were treated with duloxetine at $40-60 \mathrm{mg} / \mathrm{d}$ for 3 months until the end of the second sex hormone test. During this period, appropriate benzodiazepines and other drugs were used for adjuvant therapy depending on the patients' conditions.

\section{Parameters}

General information about all the patients was collected, including their gender, age, height, weight, education level, occupation (workers, farmers, cadres, retired, none, and other), smoking and drinking habits (judgment standard of history of smoking: smoking more than one cigarette a day, continuous/cumulative 6 months; history of drinking criterion: more than $500 \mathrm{~g} / 350 \mathrm{~g}$ [male/ female] per week and persisting for longer than 5 years), complications (mainly for high blood pressure, diabetes, coronary heart disease, stroke, none, and others; the judgment criterion is based on the diagnosis of the corresponding disease or the usage of related drugs), marital status, and records of the patients' use of antidepressants in the last week.

\section{Detection of sex hormone levels}

Outpatients were tested for sex hormone levels on the same day. Inpatients with recurrent depressive disorder underwent the first assessment of sex hormone levels within $24 \mathrm{~h}$ of admission and the second assessment of sex hormone levels after 3 months of treatment. The 5 $\mathrm{mL}$ of cubital venous blood between 8 and 10 am was taken on an empty stomach. The magnetic particle-based chemiluminescence method was used to detect samples using a chemiluminescence detector (AutoLumo A200) according to the instructions of the adrenocorticotropic hormone detection kit (ACTH CLIA Microparticles). 


\section{Statistical analysis}

The SPSS (v.22.0; IBM Corp., Armonk, NY, USA) was used to analyze the data collected. A chi-squared test or Fisher's exact probability was performed to compare the count data between the two groups. Pearson's correlation analysis was applied to analyze the correlation between sex hormone levels and age and body mass index (BMI). Spearman's correlation analysis was used to estimate the correlation between sex hormone levels and classification variables such as occupation, as well as the correlation between the severity of depression and related factors. Sex hormone levels in different age groups were compared by one-way analysis of variance, followed by Bonferroni's correction. Sex hormone levels were compared between the first-episode and recurrent groups using independent $t$-tests. The comparison of sex hormones in the recurrent group between pre- and posttreatment was performed by a paired-sample $t$-test with the test standard $\alpha=0.05$.

\section{Results}

\section{Case data}

The clinical data of the included cases are shown in Table 1. A total of 169 subjects were included in the

Table 1 Clinical data of the cases

\begin{tabular}{|c|c|c|c|c|c|}
\hline \multirow[t]{2}{*}{ Variables } & & \multicolumn{2}{|l|}{ Cases } & \multirow[t]{2}{*}{$x^{2}$} & \multirow[t]{2}{*}{$P$} \\
\hline & & First-Episode & Recurrence & & \\
\hline \multirow[t]{4}{*}{ Age } & & & & 0.905 & 0.636 \\
\hline & $<45$ & 48 & 37 & & \\
\hline & $45-55$ & 23 & 19 & & \\
\hline & $>55$ & 20 & 22 & & \\
\hline \multicolumn{6}{|c|}{ Smoking and drinking habit } \\
\hline & Yes & 0 & 3 & - & 0.096 \\
\hline & No & 91 & 75 & & \\
\hline \multirow[t]{6}{*}{ Marital status } & & & & 12.880 & $0.001^{*}$ \\
\hline & Married & 81 & 72 & & \\
\hline & Unmarried & 9 & 0 & & \\
\hline & Divorce & 0 & 2 & & \\
\hline & Remarriage & 1 & 3 & & \\
\hline & Widowed & 0 & 1 & & \\
\hline \multirow[t]{9}{*}{ Occupation } & & & & 26.422 & $0.000^{*}$ \\
\hline & Worker & 20 & 32 & & \\
\hline & Farmer & 10 & 3 & & \\
\hline & Cadre & 6 & 10 & & \\
\hline & Retirement & 15 & 6 & & \\
\hline & Student & 15 & 11 & & \\
\hline & Staff & 11 & 16 & & \\
\hline & None & 7 & 0 & & \\
\hline & Other & 7 & 0 & & \\
\hline \multirow[t]{7}{*}{ Complication } & & & & 8.797 & $0.015^{*}$ \\
\hline & Hypertension & 1 & 0 & & \\
\hline & Diabetes & 1 & 2 & & \\
\hline & Cardiopathy & 0 & 1 & & \\
\hline & None & 89 & 68 & & \\
\hline & Other & 0 & 4 & & \\
\hline & Multi-symptom & & & & \\
\hline $\mathrm{BMI}\left(\mathrm{kg} / \mathrm{m}^{2}\right)$ & & $23.48 \pm 2.68$ & $24.24 \pm 3.54$ & -1.595 & 0.113 \\
\hline \multirow[t]{3}{*}{ Antidepressant use } & & & & 66.97 & $0.000^{*}$ \\
\hline & Yes & 22 & 68 & & \\
\hline & No & 69 & 10 & & \\
\hline
\end{tabular}

The statistical software did not give a corresponding value (-); Fisher's exact probability was performed $(*)$. BMI: body mass index 
study. The average age of the first-episode group was $42.98 \pm 14.84$ years, ranging from 16 to 83 years. That of the recurrent group was $48.02 \pm 12.59$ years, with the youngest being 27 years old and the oldest 76 years old. There were no significant differences in age, smoking and drinking habits, and BMI $(P>0.05)$ between the first-episode and recurrent groups. Differences in marital status, occupation, and complications between the first-episode and recurrent groups were observed $(P<0.05)$.

\section{Correlation analysis of sex hormones and sociodemographic variables}

This correlation analysis (Table 2) showed that the estradiol level was negatively correlated with age $(r=-0.267, P=0.000)$ and the prolactin level was positively correlated with occupation $(r=0.157, P=0.041)$.

\section{Correlation analysis of the degree of depression with age} and sex hormones in females

The severity of depression in females was negatively correlated with age $(r=-0.205, P=0.007)$, but it exhibited no significant correlation with occupation, smoking and drinking habits, comorbidities, and serum progesterone, prolactin, estradiol, and testosterone levels (all $P>0.05$; Table 3).

\section{Sex hormone levels in females with depression in different age groups}

As shown in Table 4, in the first-episode group, the serum progesterone level in the young group of females with depression was significantly higher than that in the elderly group $(P<0.05)$; There was no significant difference in prolactin levels among the young, perimenopausal, and elderly groups $(P>0.05)$; The estradiol level in the young group was significantly upregulated compared to

Table 2 The correlation between sex hormones and sociodemographic variables

\begin{tabular}{|c|c|c|c|c|c|}
\hline Sex hormones & Age & $\mathrm{BMI}\left(\mathrm{kg} / \mathrm{m}^{2}\right)$ & Occupation & $\begin{array}{l}\text { Smoking and drinking } \\
\text { habit }\end{array}$ & Complication \\
\hline$P$ & -0.087 & 0.018 & 0.008 & -0.005 & 0.044 \\
\hline$P R L$ & -0.009 & -0.027 & $0.157^{b}$ & -0.105 & -0.039 \\
\hline $\mathrm{E}_{2}$ & $-0.267^{a}$ & -0.055 & 0.119 & 0.055 & 0.057 \\
\hline $\mathrm{T}$ & -0.053 & -0.094 & 0.100 & 0.042 & -0.041 \\
\hline
\end{tabular}

$\mathrm{a}, p=0.000 ; \mathrm{b}, P=0.041 . \mathrm{P}$ : progesterone; PRL: prolactin; E2: estradiol; T: testosterone; $\mathrm{BMI}$ : body mass index

Table 3 The correlation between the degree of depression and related factors in females

\begin{tabular}{lccllllll}
\hline Items & Age & Job & $\begin{array}{l}\text { Smoking and } \\
\text { drinking habit }\end{array}$ & Complication & $\boldsymbol{P}$ & PRL & $\mathbf{E}_{\mathbf{2}}$ & T \\
\hline Severity & -0.205 & -0.005 & 0.044 & 0.056 & 0.084 & 0.021 & 0.103 \\
$P$ & 0.007 & 0.945 & 0.561 & 0.464 & 0.275 & 0.784 & 0.181 & 0.097 \\
\hline
\end{tabular}

P: progesterone; PRL: prolactin; E2: estradiol; T: testosterone

Table 4 Sex hormone levels in females of different ages suffering from depression

\begin{tabular}{|c|c|c|c|c|c|c|}
\hline Variables & Young group & Perimenopausal group & elderly group & $P 1$ & $P 2$ & P3 \\
\hline First-Episode & $n=48$ & $n=23$ & $n=20$ & & & \\
\hline$P\left(n g \cdot m L^{-1}\right)$ & $3.17 \pm 5.03$ & $1.35 \pm 2.51$ & $0.41 \pm 0.29$ & 0.064 & 0.010 & 0.429 \\
\hline$P R L\left(u l U \cdot m L^{-1}\right)$ & $685.58 \pm 1153.46$ & $630.23 \pm 1308.88$ & $690.35 \pm 972.45$ & 0.851 & 0.988 & 0.867 \\
\hline $\mathrm{E}_{2}\left(\mathrm{pg} \cdot \mathrm{mL}^{-1}\right)$ & $77.19 \pm 72.48$ & $68.68 \pm 70.81$ & $33.05 \pm 18.43$ & 0.602 & 0.014 & 0.076 \\
\hline $\mathrm{T}\left(\mathrm{ng} \cdot \mathrm{mL}^{-1}\right)$ & $0.76 \pm 2.42$ & $0.37 \pm 0.13$ & $0.51 \pm 0.77$ & 0.399 & 0.611 & 0.810 \\
\hline The-Recurrence & $n=37$ & $\mathrm{n}=19$ & $n=22$ & & & \\
\hline$P\left(n g \cdot m L^{-1}\right)$ & $3.93 \pm 7.94$ & $2.19 \pm 4.49$ & $0.54 \pm 0.28$ & 0.303 & 0.037 & 0.376 \\
\hline PRL (ulU. mL $L^{-1}$ ) & $392.28 \pm 357.01$ & $697.27 \pm 770.34$ & $530.56 \pm 633.86$ & 0.058 & 0.364 & 0.347 \\
\hline$E_{2}\left(p g \cdot m L^{-1}\right)$ & $81.12 \pm 77.70$ & $33.84 \pm 25.09$ & $19.77 \pm 11.20$ & 0.003 & 0.000 & 0.421 \\
\hline $\mathrm{T}\left(\mathrm{ng} \cdot \mathrm{mL}^{-1}\right)$ & $0.98 \pm 1.48$ & $0.71 \pm 1.54$ & $0.44 \pm 0.77$ & 0.480 & 0.133 & 0.509 \\
\hline
\end{tabular}

P1: comparison between the young group and the perimenopausal group; $P 2$ : comparison between young group and elderly group; $P 3$ : comparison between perimenopausal group and elderly group. P: progesterone; PRL: prolactin; E2: estradiol; T: testosterone 
the elderly group $(P<0.05)$, and the estradiol level in the perimenopausal group was higher than that in the elderly group $(P>0.05)$; The testosterone level in the young and elderly groups was higher than that in the perimenopausal group, whereas there was no significant difference among the three groups $(P>0.05)$.

In the recurrent group. the serum progesterone level in the young group was significantly elevated in contrast to the elderly group $(P<0.05)$, and the serum progesterone level in the perimenopausal group was higher than that in the elderly group $(P>0.05)$; No significant difference was observed in prolactin and testosterone levels among

Table 5 Comparison of sex hormone levels in females with firstepisode and recurrent depression

\begin{tabular}{|c|c|c|c|c|}
\hline Variables & First-Episode & Recurrence & $t$ & $P$ \\
\hline Young group & $=48$ & $n=37$ & & \\
\hline$P\left(n g \cdot \mathrm{mL}^{-1}\right)$ & $3.15 \pm 5.10$ & $3.98 \pm 7.73$ & -0.581 & 0.563 \\
\hline $\operatorname{PRL}\left(\mathrm{ulU} \cdot \mathrm{mL}^{-1}\right)$ & $618.54 \pm 1147.57$ & $388.41 \pm 347.90$ & 1.204 & 0.232 \\
\hline$E_{2}\left(p g \cdot m L^{-1}\right)$ & $75.83 \pm 74.00$ & $80.05 \pm 75.77$ & -0.255 & 0.799 \\
\hline$T\left(\mathrm{ng} \cdot \mathrm{mL}^{-1}\right)$ & $0.79 \pm 2.51$ & $0.98 \pm 1.48$ & -0.419 & 0.677 \\
\hline $\begin{array}{l}\text { Perimenopausal } \\
\text { group }\end{array}$ & $n=27$ & $n=19$ & & \\
\hline$P\left(n g \cdot m L^{-1}\right)$ & $1.35 \pm 2.51$ & $2.10 \pm 4.39$ & -0.710 & 0.482 \\
\hline PRL $\left(u l U \cdot m L^{-1}\right)$ & $630.23 \pm 1308.88$ & $697.27 \pm 770.34$ & -0.198 & 0.844 \\
\hline$E_{2}\left(p g \cdot m L^{-1}\right)$ & $68.68 \pm 70.81$ & $33.38 \pm 24.51$ & 2.284 & 0.030 \\
\hline$T\left(\mathrm{ng} \cdot \mathrm{mL}^{-1}\right)$ & $0.37 \pm 0.13$ & $0.69 \pm 1.50$ & -0.930 & 0.364 \\
\hline Elderly group & $n=19$ & $n=22$ & & \\
\hline$P\left(n g \cdot m^{-1}\right)$ & $0.41 \pm 0.29$ & $0.54 \pm 0.28$ & -1.465 & 0.151 \\
\hline PRL (ulU. $\left.\mathrm{mL}^{-1}\right)$ & $690.35 \pm 972.45$ & $530.56 \pm 633.86$ & 0.631 & 0.531 \\
\hline$E_{2}\left(p g \cdot \mathrm{mL}^{-1}\right)$ & $33.05 \pm 18.43$ & $19.77 \pm 11.20$ & 2.832 & 0.007 \\
\hline $\mathrm{T}\left(\mathrm{ng} \cdot \mathrm{mL}^{-1}\right)$ & $0.51 \pm 0.77$ & $0.44 \pm 0.77$ & 0.291 & 0.772 \\
\hline
\end{tabular}

P: progesterone; PRL: prolactin; E2: estradiol; T: testosterone the young, perimenopausal, and elderly groups $(P>0.05)$; The estradiol level in the young group was significantly higher than that in the perimenopausal and elderly groups $(P<0.05)$, and the estradiol level in the recurrent perimenopausal group was higher than that in the elderly group $(P>0.05)$.

\section{Comparison of sex hormone levels in females with first-episode and recurrent depression}

The estradiol level in the first-episode perimenopausal group was obviously enhanced compared to the recurrent perimenopausal group $(P<0.05$; Table 5$)$. The estradiol level in females with depression in the firstepisode elderly group was significantly higher than that in the recurrent elderly group $(P<0.05$; Table 5$)$. There was no significant difference in other sex hormone levels between the first-episode and recurrent groups (all $P>0.05$; Table 5).

\section{Comparison of sex hormone levels in the recurrent group before and after treatment}

After three months of treatment, the serum sex hormone level in the recurrent groups of all ages changed, but there was no significant difference $(P>0.05$; Table 6$)$. It was observed that treatment led to an increase in the progesterone level in the young group and a reduced progesterone concentration in the perimenopausal group. After treatment, prolactin levels increased in the young and elderly groups and decreased in the perimenopausal group. Estradiol levels decreased in the young group and increased in the perimenopausal and elderly groups after the patients received treatment. No overt alteration was observed in testosterone levels among the three groups before and after treatment.

Table 6 Comparison of sex hormone levels in the recurrent group before and after treatment

\begin{tabular}{|c|c|c|c|c|c|}
\hline & Variables & Prior treatment & Post-treatment & $t$ & $P$ \\
\hline \multirow[t]{4}{*}{ Young group $(n=37)$} & $\mathrm{P}\left(\mathrm{ng} \cdot \mathrm{mL}^{-1}\right)$ & $3.98 \pm 7.73$ & $5.29 \pm 7.99$ & -0.764 & 0.449 \\
\hline & PRL (ulU. mL $\left.{ }^{-1}\right)$ & $388.41 \pm 347.90$ & $590.48 \pm 1257.69$ & -0.987 & 0.330 \\
\hline & $\mathrm{E}_{2}\left(\mathrm{pg} \cdot \mathrm{mL}^{-1}\right)$ & $80.05 \pm 75.77$ & $66.76 \pm 64.80$ & 0.924 & 0.362 \\
\hline & $T\left(\mathrm{ng} \cdot \mathrm{mL}^{-1}\right)$ & $0.98 \pm 1.48$ & $1.15 \pm 1.83$ & -0.671 & 0.507 \\
\hline \multirow[t]{4}{*}{ Perimenopausal group $(n=19)$} & $P\left(n g \cdot m L^{-1}\right)$ & $1.43 \pm 3.29$ & $0.55 \pm 0.28$ & 1.152 & 0.265 \\
\hline & PRL (ulU. $\left.m L^{-1}\right)$ & $668.58 \pm 786.31$ & $371.45 \pm 245.61$ & 1.632 & 0.120 \\
\hline & $E_{2}\left(p g \cdot m L^{-1}\right)$ & $30.10 \pm 20.19$ & $35.21 \pm 32.43$ & -0.749 & 0.463 \\
\hline & $T\left(\mathrm{ng} \cdot \mathrm{mL}^{-1}\right)$ & $0.72 \pm 1.54$ & $0.63 \pm 1.13$ & 0.192 & 0.850 \\
\hline \multirow[t]{4}{*}{ Elderly group $(n=22)$} & $P\left(n g \cdot m L^{-1}\right)$ & $0.54 \pm 0.28$ & $0.57 \pm 0.30$ & -0.616 & 0.544 \\
\hline & PRL (ulU. mL $\left.{ }^{-1}\right)$ & $530.56 \pm 633.86$ & $637.63 \pm 868.49$ & -0.669 & 0.511 \\
\hline & $E_{2}\left(p g \cdot m L^{-1}\right)$ & $19.77 \pm 11.20$ & $24.07 \pm 11.75$ & -1.155 & 0.261 \\
\hline & $\mathrm{T}\left(\mathrm{ng} \cdot \mathrm{mL}^{-1}\right)$ & $0.44 \pm 0.77$ & $0.35 \pm 0.17$ & 0.479 & 0.637 \\
\hline
\end{tabular}

P: progesterone; PRL: prolactin; E2: estradiol; T: testosterone 


\section{Discussion}

Epidemiological data show that about $20 \%$ of females suffer from major depression at some point during their lives. Notably, for some women, depression can appear or worsen in different periods, during which hormone levels dynamically change, including premenstrual, perinatal, and perimenopausal periods [17]. Mounting evidence has proved that sex hormones participate in the physiological and pathological development of depression in females $[14,18,19]$. Nevertheless, the relationship between depression and sex hormones in women remains to be further studied.

There are many factors that induce depression. For example, genetic factors-that is, congenital defectsmay lead to weaker stress tolerance. Studies have confirmed that depression has a certain family genetic risk. However, the specific cause is not clear. Several studies have also shown that there is a link between sex hormones and depression [20]. Some studies have suggested that abnormal sex hormone levels may be a clinical phenomenon in those suffering from depression [21]. This study found that progesterone and estradiol levels were significantly different in the first episode, recurrence, and among different age groups. This indicates a close relationship between depression and sex hormones. The role of sex hormones in regulating females' emotions has been confirmed by many studies [22, 23]. As steroid hormones, progesterone and estradiol play vital roles in regulating brain morphology and function. Fluctuations in sex hormone levels can cause changes in the neurotransmitter system, thereby potentially and lastingly affecting mood and behavior. Estradiol is known to have protective effects on the nerves, especially for perimenopausal and elderly women $[24,25]$. It has been found that $\gamma$-aminobutyric acid (GABA) or glutamic acid can affect mood by regulating the activity of the lateral reins $(\mathrm{LHb})$ in the brain region [26, 27], and sex hormones have been found to interact with GABA and brain-derived neurotrophic factors in a way that affects mood [28-32]. In addition, certain sex hormones-such as progesterone, which is a positive phase-change structural regulator of GABA receptors, and it has been found that progesterone levels increased after treatment with antidepressants [33]. However, some studies on perimenopausal depression in females show that perimenopausal depression has nothing to do with the fluctuation in sex hormone levels, which is caused by the difficulty in measuring sex hormones [34]. A lot of research has been conducted on hormone therapy for people with depression. The vast majority of studies suggest that a combination of hormone therapy or medication should be given to those who are eligible, a treatment that deserves the attention of psychiatrists [35]. Of course, abnormal sex hormone levels in patients with depression are not only manifested in females, but also in males [36, 37]. And various sex hormones have a certain impact on people's mental health to some extent, especially the elderly[38]. Moreover, the severity of depression in females was found to be negatively correlated with age, suggesting that young women were more prone to depression [39]. The severity of depression in elderly women seems to have received a lot of attention [40]. However, studies have pointed out that the increase of depression in elderly women was more strongly related to physical diseases (such as chronic bronchitis and obstructive emphysema, hypertension, cerebrovascular disease, and cataract) than to age [41].

From the life course of female patients with depression, they have experienced from relatively high sex hormone levels when they were young, to relatively low sex hormone levels during perimenopausal period, and then to further low sex hormone levels in the old age, so it can be seen that the sex hormone levels of female patients with depression change with age. The results of this study showed that sex hormone levels in females with depression were negatively correlated with age. As age increases, these sex hormone levels decrease, especially estradiol. This study also found that the progesterone and estradiol levels in young females with depression were significantly higher than those in the elderly group, regardless of the first episode or recurrence. Changes in hormone levels with age were also seen in healthy females, but changes in females with depression were more dramatic than those in healthy females, and these fluctuations in sex hormone levels have the potential to induce negative emotions [42]. Related studies have found that sex hormones play different roles in women with depression in different age groups [43].

The study also noted differences in sex hormone levels of females with depression in the first episode and in those with recurrent depression. We found that in the perimenopausal group, females with the first episode exhibited higher estradiol levels than those with recurrence. We believe that this difference in sex hormone levels is mainly due to the use of antidepressants. After all, patients with recurrent depression actively take antidepressants when their symptoms appear and do not come to the hospital until the drugs are ineffective. Accordingly, antidepressants have been taken for a period prior to the detection of sex hormones. Relevant studies have shown that antidepressants can affect sex hormone levels $[44,45]$. Hence, it is reasonable to believe that the difference in estradiol levels between females with the first episode and recurrence of depression was due to the use of antidepressants. Of note, it has been proved that duloxetine may have 
endocrine-disrupting effects on the synthesis of steroids $[46,47]$. In view of this, we speculated that the changes in sex hormone levels were likely to be attributed to the regulatory role of duloxetine in the endocranium. However, it remains to be investigated whether all antidepressants can affect sex hormone levels and whether these antidepressants have similar effects.

There are some limitations to this study. It lacks healthy controls and is limited to the small sample size, which makes the conclusions of this study less convincing. We intend to expand the sample size and add hierarchical analysis in the in-depth study. Furthermore, considering that many factors are responsible for depression-including biological, psychological, social environment, and genetic factors-patients with depression triggered by different situations are divided into corresponding groups to eliminate the interference before the analysis. Future research can further explore recurrence factors on the influence of sex hormone levels in females with depression. In addition, the effects of drug use, severity, and accompanying symptoms of anxiety on sex hormones in patients with first episode and recurrence can also be studied to make the study more comprehensive.

\section{Conclusions}

The severity of depression in females was negatively related to age; the estrogen level in women with depression was negatively related to age; recurrent depression also had a certain effect on the sex hormones of females with depression. These results laid a foundation for the mechanism of sex hormones in depression and brought good news for the prevention and treatment of depression.

\section{Abbreviations}

BMI: Body mass index; GABA: $y$ - aminobutyric acid; P: Progesterone; PRL: Prolactin; E2: Estradiol; T: Testosterone.

\section{Acknowledgements}

None.

\section{Authors' contributions}

$\mathrm{RL}$ collected the data, analyzed the data, and drafted the manuscript. YS analyzed the data and revised the manuscript. JWL analyzed the data and helped to draft the manuscript. YY drafted the discussion. LLS participated in the design of the study and revised the discussion. YGL and XYY participated in the design of the study and data collection. WYM conceived of the study, participated in its design and coordination, and reviewed the manuscript. ZJY participated in the conception and design of the study, reviewed and revised the manuscript. All authors read and approved the final manuscript.

\section{Funding}

None.

\section{Availability of data and materials}

The datasets used and/or analyzed during the current study available from the corresponding author on reasonable request.

\section{Declarations}

\section{Ethics approval and consent to participate}

The research protocol of this study was approved by the Ethics Committee of the Kailuan Mental Health Center Affiliated to North China University of Science and Technology. And the written informed consent to participate was provided by all participants.

\section{Consent for publication}

The written informed consent for publication was obtained from all participants.

\section{Competing of interests}

All authors have no potential competing of interests.

\section{Author details}

${ }^{1}$ Department of Adult Psychiatry, Second People's Hospital of Huizhou, Huizhou, China. ${ }^{2}$ Department of Clinical Psychology, Kailuan Mental Health Center Affiliated to North China University of Science and Technology, Tangshan, China. ${ }^{3}$ School of Psychology and Mental Health, North China University of Science and Technology, Tangshan, China. ${ }^{4}$ Department of Geriatric Psychiatry, Second People's Hospital of Huizhou, Huizhou, China. ${ }^{5}$ School of Basic Medical Sciences, Peking University Health Science Center, Beijing, China. ${ }^{6}$ Department of Mood Disorders, Tianjin Mental Health Centre, Tianjin, China. ${ }^{7}$ Department of Clinical Psychology, Kailuan Mental Health Center Affiliated to North China University of Science and Technology, Tangshan, China.

Received: 3 July 2020 Accepted: 9 May 2021

Published online: 22 May 2021

References

1. Friedrich MJ. Depression is the leading cause of disability around the World. JAMA. 2017;317(15):1517.

2. Holden C. Mental health. Global survey examines impact of depression. Science. 2000;288(5463):39-40.

3. Sassarini DJ. Depression in midlife women. Maturitas. 2016;94:149-54.

4. Wesselhoeft R, Pedersen CB, Mortensen PB, Mors O, Bilenberg N. Genderage interaction in incidence rates of childhood emotional disorders. Psychol Med. 2015;45(04):829-39.

5. Skovlund CW, Mørch LS, Kessing LV, Lidegaard Ø. Association of hormonal contraception with depression. JAMA Psychiatry. 2016;73(11):1154-62.

6. Cover KK, Maeng LY, Lebrón-Milad K, Milad MR. Mechanisms of estradiol in fear circuitry: implications for sex differences in psychopathology. Transl Psychiatry. 2014;4(8):e422.

7. Li SH, Graham BM. Why are women so vulnerable to anxiety, traumarelated and stress-related disorders? The potential role of sex hormones. Lancet Psychiatry. 2017;4(1):73-82.

8. Epperson CN, Steiner M, Hartlage SA, Eriksson E, Schmidt PJ, Jones I, Yonkers KA. Premenstrual dysphoric disorder: evidence for a new category for DSM-5. Am J Psychiatry. 2012;169(5):465-75.

9. Freeman EW, Sammel MD, Boorman DW, Zhang R. Longitudinal pattern of depressive symptoms around natural menopause. JAMA Psychiatry. 2014;71(1):36-43.

10. Altemus M, Sarvaiya N, Neill Epperson C. Sex differences in anxiety and depression clinical perspectives. Front Neuroendocrinol. 2014;35(3):320-30.

11. Gordon JL, Girdler SS, Meltzer-Brody SE, Stika CS, Thurston RC, Clark CT, Prairie BA, Moses-Kolko E, Joffe H, Wisner KL. Ovarian hormone fluctuation, neurosteroids, and HPA axis dysregulation in perimenopausal depression: a novel heuristic model. Am J Psychiatry. 2015;172(3):227-36.

12. Cohen LS, Soares CN, Poitras JR, Prouty J, Alexander AB, Shifren JL. Short-term use of estradiol for depression in perimenopausal and postmenopausal women: a preliminary report. Am J Psychiatry. 2003;160(8):1519-22

13. de Villiers TJ, Hall JE, Pinkerton JV, Perez SC, Rees M, Yang C, Pierroz DD. Revised global consensus statement on menopausal hormone therapy. Maturitas. 2016;91:153-5. 
14. Szpunar MJ, Parry BL. A systematic review of cortisol, thyroid-stimulating hormone, and prolactin in peripartum women with major depression. Arch Womens Ment Health. 2018;21(2):149-61.

15. Del Rio JP, Alliende MI, Molina N, Serrano FG, Molina S, Vigil P. Steroid hormones and their action in Women's brains: the importance of hormonal balance. Front Public Health. 2018;6:141.

16. Yin W, Gore AC. Neuroendocrine control of reproductive aging: roles of GnRH neurons. Reproduction. 2006;131(3):403-14.

17. Bromberger JT, Epperson CN. Depression during and after the Perimenopause: impact of hormones, genetics, and environmental determinants of disease. Obstet Gynecol Clin N Am. 2018;45(4):663-78.

18. Slavich GM, Sacher J. Stress, sex hormones, inflammation, and major depressive disorder: Extending Social Signal Transduction Theory of Depression to account for sex differences in mood disorders. Psychopharmacology. 2019;236(10):3063-79.

19. Li D, Li Y, Chen Y, Li H, She Y, Zhang X, Chen S, Chen W, Qiu G, Huang H. Neuroprotection of reduced thyroid hormone with increased estrogen and progestogen in postpartum depression. 2019;39(9).

20. Erdincler D, Bugay G, Ertan T, Eker E. Depression and sex hormones in elderly women. Arch Gerontol Geriatr. 2004;39(3):239-44

21. Zarate S, Stevnsner T, Gredilla R. Role of estrogen and other sex hormones in brain aging. Neuroprotection and DNA repair. Front Aging Neurosci. 2017;9:430

22. Solomon MB, Herman JP. Sex differences in psychopathology: of gonads, adrenals and mental illness. Physiol Behav. 2009;97(2):250-8.

23. Graham BM, Denson TF, Barnett J, Calderwood C, Grisham JR. Sex hormones are Associated With Rumination and Interact With Emotion Regulation Strategy Choice to Predict Negative Affect in Women Following a Sad Mood Induction. Front Psychol. 2018;9:937.

24. Cao XJ, Huang XC, Wang X. Effectiveness of Chinese herbal medicine granules and traditional Chinese medicine-based psychotherapy for perimenopausal depression in Chinese women: a randomized controlled trial. Menopause. 2019;26(10):1193-203.

25. Natari RB, Clavarino AM, McGuire TM, Dingle KD, Hollingworth SA. The bidirectional relationship between vasomotor symptoms and depression across the menopausal transition: a systematic review of longitudinal studies. Menopause. 2018;25(1):109-20.

26. Shabel SJ, Proulx CD, Piriz J, Malinow R. Mood regulation. GABA/glutamate co-release controls habenula output and is modified by antidepressant treatment. Science. 2014;345(6203):1494-8.

27. Lener MS, Niciu MJ, Ballard ED, Park M, Park LT, Nugent AC, Zarate CA Jr. Glutamate and Gamma-Aminobutyric Acid Systems in the Pathophysiology of Major Depression and Antidepressant Response to Ketamine. Biol Psychiatry. 2017:81(10):886-97.

28. Zhang L, Hernandez VS, Swinny JD, Verma AK, Giesecke T, Emery AC, Mutig K, Garcia-Segura LM, Eiden LE. A GABAergic cell type in the lateral habenula links hypothalamic homeostatic and midbrain motivation circuits with sex steroid signaling. Transl Psychiatry. 2018;8(1):50.

29. Hill RA. Interaction of sex steroid hormones and brain-derived neurotrophic factor-tyrosine kinase B signalling: relevance to schizophrenia and depression. J Neuroendocrinol. 2012;24(12):1553-61.

30. Morris RG, Anderson E, Lynch GS, Baudry M. Selective impairment of learning and blockade of long-term potentiation by an N-methyl-Daspartate receptor antagonist, AP5. Nature. 1986;319(6056):774-6.

31. Murphy DD, Cole NB, Greenberger V, Segal M. Estradiol increases dendritic spine density by reducing GABA neurotransmission in hippocampal neurons. J Neurosci. 1998;18(7):2550-9.

32. Hu M, Watson CJ, Kennedy RT, Becker JB. Estradiol attenuates the $\mathrm{K}+$-induced increase in extracellular GABA in rat striatum. Synapse. 2006:59(2):122-4.
33. Strohle A, Romeo E, Hermann B, Pasini A, Spalletta G, di Michele F, Holsboer F, Rupprecht R. Concentrations of 3 alpha-reduced neuroactive steroids and their precursors in plasma of patients with major depression and after clinical recovery. Biol Psychiatry. 1999;45(3):274-7.

34. Frokjaer VG, Pinborg A, Holst KK, Overgaard A, Henningsson S, Heede $M$, Larsen EC, Jensen PS, Agn M, Nielsen AP, et al. Role of serotonin transporter changes in depressive responses to sex-steroid hormone manipulation: a positron emission tomography study. Biol Psychiatry. 2015;78(8):534-43.

35. Jahn H. Steroid-synthesis inhibition in depression: a good idea? Lancet Psychiatry. 2016;3(2):92-3.

36. Monteagudo PT, Falcão AA, Verreschi IT, Zanella MT. The imbalance of sex-hormones related to depressive symptoms in obese men. Aging Male. 2016;19(1):20-6.

37. Stanikova D, LuckT, Bae YJ, Thiery J, Ceglarek U, Engel C, Enzenbach C, Wirkner K, Stanik J, Kratzsch J, et al. Increased estrogen level can be associated with depression in males. Psychoneuroendocrinology. 2018:87:196-203.

38. Castanho TC, Moreira PS, Portugal-Nunes C, Novais A, Costa PS, Palha JA, Sousa N, Santos NC. The role of sex and sex-related hormones in cognition, mood and well-being in older men and women. Biol Psychol. 2014;103:158-66.

39. Bevilacqua LA, Dulak D, Schofield E, Starr TD, Nelson CJ, Roth AJ, Holland JC, Alici Y. Prevalence and predictors of depression, pain, and fatigue in older- versus younger-adult cancer survivors. Psycho-oncology. 2018;27(3):900-7.

40. Sengupta P, Benjamin Al. Prevalence of depression and associated risk factors among the elderly in urban and rural field practice areas of a tertiary care institution in Ludhiana. Indian J Public Health. 2015;59(1):3-8.

41. Tang M, Liu X-H, Han H-Y, Tang M-M, Wang Y-F, Zhang L-Z. Prevalence of depressive disorders among residents aged 55 or above in Chengdu area. Chin Mental Health J. 2001;02:103-6.

42. de Kruif M, Molendijk ML, Haffmans PM, Spijker AT. Depression during the perimenopause. Tijdschr Psychiatr. 2015;57(11):795-804.

43. Breuer B, Martucci C, Wallenstein S, Likourezos A, Libow LS, Peterson A, Zumoff B. Relationship of endogenous levels of sex hormones to cognition and depression in frail, elderly women. Am J Geriatr Psychiatry. 2002;10(3):311-20.

44. Dording CM, Boyden SD. Depression, antidepressants, and sexual functioning. In: The Massachusetts General Hospital Guide to Depression: New Treatment Insights and Options. edn. Edited by Shapero BG, Mischoulon D, Cusin C. Cham: Springer International Publishing; 2019:123-137.

45. Damoiseaux VA, Proost JH, Jiawan VC, Melgert BN. Sex differences in the pharmacokinetics of antidepressants: influence of female sex hormones and oral contraceptives. Clin Pharmacokinet. 2014;53(6):509-19.

46. Islin J, Munkboel CH, Styrishave B. Steroidogenic disruptive effects of the serotonin-noradrenaline reuptake inhibitors duloxetine, venlafaxine and tramadol in the H295R cell assay and in a recombinant CYP17 assay. Toxicol In Vitro: Int J Publ Assoc BIBRA. 2018;47:63-71.

47. Lupu D, Sjödin MOD, Varshney M, Lindberg J, Loghin F, Rüegg J. Fluoxetine modulates sex steroid levels in vitro. Clujul Med. 2017;90(4):420-4

\section{Publisher's Note}

Springer Nature remains neutral with regard to jurisdictional claims in published maps and institutional affiliations. 